\title{
Producción Manufacturera Colonial en la Provincia del Socorro, Colombia: Centros de Producción y Mercados
}

René Álvarez Orozco

\begin{abstract}
RESUMEN
El objetivo de este artículo es determinar y reconocer la importancia de la producción económica artesanal de la provincia del Socorro, en los mercados local y nacional en el periodo colonial. Con ello, no sólo se pretende explorar y analizar el sector de la actividad textil, sino también el de las manufacturas y demás productos elaborados por los artesanos de dicha provincia.

De esta manera, se pretende esclarecer el proceso de evolución de tal producción autóctona y de su integración en la economía de mercado regional y nacional, enfatizando las principales modalidades y sistemas de producción utilizados en la elaboración de tejidos de algodón y lana y las diversas manufacturas como sombreros, alpargates, artículos de cuero, etc, que se constituyeron en la base del sostenimiento económico de gran parte de la población del Socorro.
\end{abstract}

DESCRIPTORES: Colombia, Economía Colonial, Manufacturas, Artesanos, Textiles.

\begin{abstract}
The objective of this article is to determine and to recognize the importance of the handmade economic production of the Socorro's county, Colombia, in the local and national markets in the colonial period. With it, it is not only sought to explore and to analyze the sector of the textile activity, but also that of the factories and other products elaborated by the artisans of the county.

This way, it is sought to clarify the process of evolution of such an autochthonous production and of their integration in the economy of regional and national market, emphasizing the main modalities and production systems used in the elaboration of cotton fabrics and wool and the diverse factories as hats, alpargates, leather articles, etc that were constituted in the base of the economic maintenance of the population's of this county great part.
\end{abstract}

KEY WORDS: Colombia, Colonial Economy, Handmade, Artisans, Textile. 


\title{
PRODUCCIÓN MANUFACTURERA COLONIAL EN LA PROVINCIA DEL SOCORRO, COLOMBIA: CENTROS DE PRODUCCIÓN Y MERCADOS
}

\author{
René Álvarez Orozco*
}

\section{La Circulación de la Producción}

La estructura espacial de la producción textil queda claramente definida en la interrelación constante entre centros productores de materia prima y aquellos encargados de su transformación. Los primeros estuvieron situados principalmente en las zonas aledañas a las poblaciones o parroquias fundadas por los vecinos que habitaban el lugar, algunos originariamente habían sido pueblos indios. Allí se desarrollaban actividades agrícolas como los cultivos de algodón, fique, caña, etc, y de tipo pecuarias como la cría de ovejas y ganado vacuno, es decir, se ocupaban específicamente de desarrollar las materias primas para la producción de manufacturas. Los días establecidos para "el mercado" en las parroquias, permitían el desplazamiento de campesinos que se acercaban desde sus parcelas para vender el producto de su trabajo familiar, a la vez que establecía conexiones con otros productores y vendedores de otras materias primas para aprovisionarse de éstas y continuar la producción doméstica. Y los segundos, ubicados en las poblaciones urbanas con mayor concentración demográfica como el Socorro, que se constituían como centro provincial, cuya función era la transformación y manufactura de la materia prima (algodón, fibras de nacuma, cuero, fique, lana, etc.) que les llegaba de los primeros, a través del trabajo familiar o industria doméstica, y en donde se concentraban gran número de comerciantes que compraban los productos ya elaborados para venderlos o transportarlos a mercados distantes, permitiendo a los socorranos en esta dinámica de intercambio comercial, participar activamente en los circuitos comerciales del Nuevo Reino que enlazaban a los centros urbanos más 
importantes de la época tales como Santa Fe, Tunja, Vélez, san Gil, Girón, Pamplona, así como a los distritos mineros del occidente(1) y a los mercados de la costa atlántica. (Ver mapa de las provincias de San Gil, Socorro y Vélez en 1795).

El producto del trabajo artesanal alcanzaba sus destinos a través de un sistema de mercadeo interior cuyo punto focal de intercambio era los mercados semanales y las ferias desarrolladas en los poblados, algo que todavía es característico en nuestros municipios; en estos mercados semanales, los pequeños campesinos y los artesanos compraban las materias primas esenciales para su labor diaria, a la vez que ofrecían sus servicios de mano de obra y vendían sus productos, resultado de la labor domiciliaria realizada por la familia. Allí en el mercado, confluían además de los campesinos y artesanos, una élite de comerciantes que intercambiaba el producto por dinero o materia prima y se encargaban trasladar la producción a otros centros comerciales de larga distancia.

Desde los centros de producción, las manufacturas (tejidos, sombreros, alpargates, frazadas, bayetas, sacos de fique, mantas, pabellones, alfombras, tapetes, colchas, cotones, zapatos de tacón, cordobanes, camisetas, paños, cinchas de monturas, etc)(2) salían y se dispersaban por el espacio económico a través de un doble movimiento: el primero tenía características locales y abastecía a los esclavos y jornaleros de las haciendas, trabajadores en el distrito minero, pobladores pobres de la ciudad y en algunos casos al ejército patriota, del cual hablaremos más adelante. No hay que olvidar que inicialmente, durante la bonanza minera en el distrito del río del Oro, las empresas agropecuarias y artesanales abastecían a los mercados de éstos centros mineros de víveres y ropas de la tierra(3). Estos sectores locales aseguraban el consumo de una buena parte de la producción. En segundo lugar, la realización de la mercancía exigía un movimiento hacia fuera del espacio transformador o productor, que a través de los 


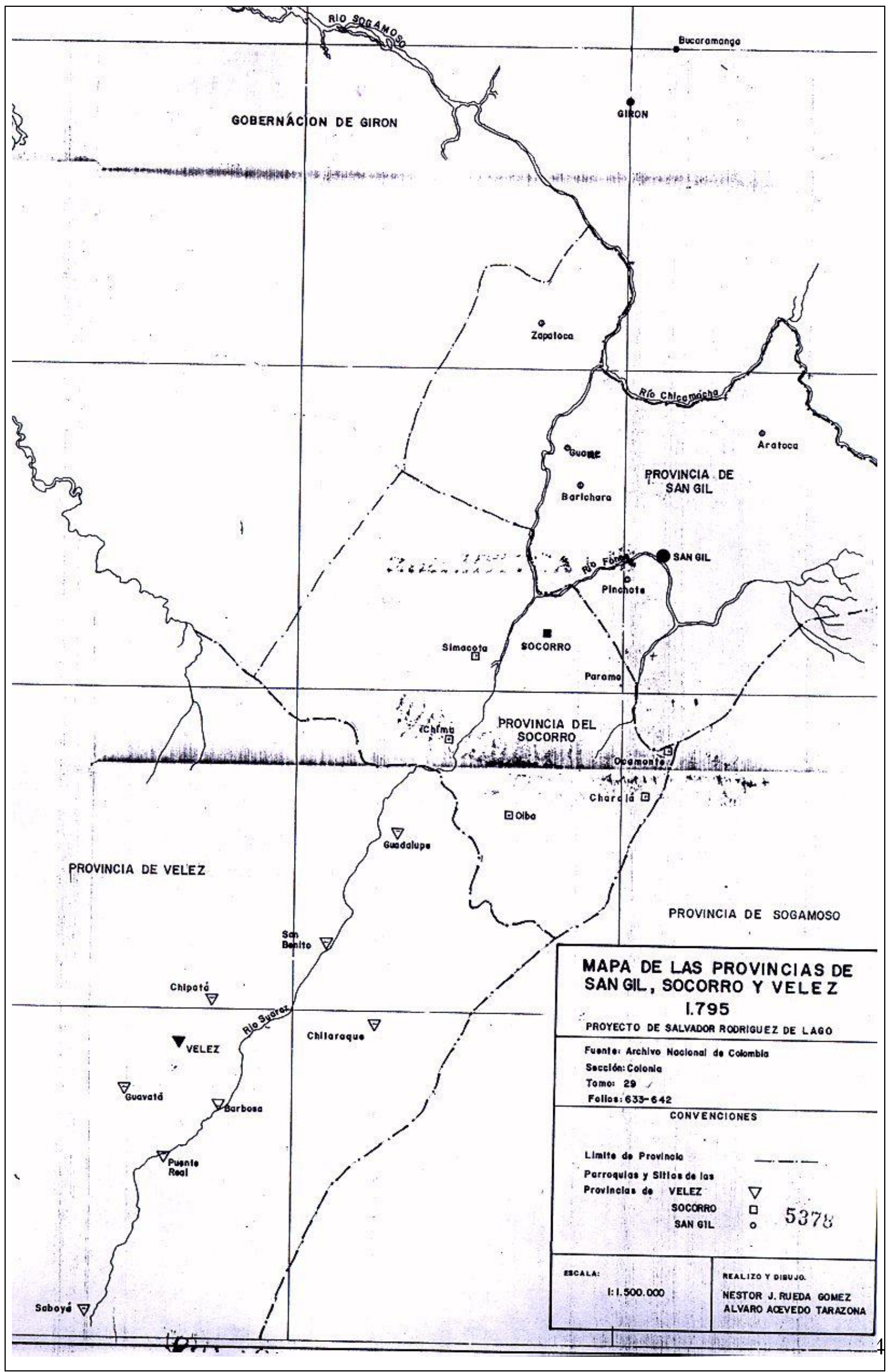


comerciantes enviaba una parte de la producción hacia mercados regionales como Boyacá, Antioquia, Cundinamarca, entre otros. Es decir, había una expansión a nivel regional e incluso nacional de la producción manufacturera. Ya en 1779, los santandereanos habían adquirido una sólida reputación como cultivadores y tejedores de algodón(4).

Vemos entonces la existencia de una cadena comercial por la cual se movilizaba la producción manufacturera socorrana, partiendo desde su lugar de origen hasta diversos puntos de acopio a nivel regional que la expandía a escala nacional, en una auténtica dinámica de intercambio comercial para la época. Los artesanos socorranos vendían sus productos a un comerciante local que los expendía a centros comerciales de mayor complejidad como Bogotá, Mompóx, Cartagena, etc, o a comerciantes de esas localidades que les compraban directamente a los artesanos de Santander. Las manufacturas que llegaban a Antioquia lo hacían por lo general por la vía Bogotá-Honda-Nare(5), o por la vía Mompox, en donde los mineros del nordeste de Antioquia intercambiaban con los artesanos santandereanos oro por sus mercancías(6).

En general, el comercio de distribución de productos internos en el periodo colonial tuvo mucha importancia, dado que jugó un papel básico en la acumulación interna de capital-dinero y en el desarrollo de la actividad mercantil, pues se abrieron nuevos espacios tendientes a la comercialización y el intercambio que redundaría en la formación de nuevas poblaciones y el crecimiento de otras.

La comercialización y la integración de los mercados regionales de corta y larga distancia, dependieron en gran medida del desarrollo de vías de comunicación entre los centros de producción y de abastecimiento. El entorno rural producía la materia prima, la cual era transformada y distribuida en los pueblos; este conjunto de procesos necesitó de una red de caminos, que acercara a las villas y poblaciones entre sí, y a éstos con los centros de consumo y distribución para 
vastas regiones del Reino(7). Así, aparte de las arterias fluviales, los caminos se constituyeron en motor de movilización de la producción agropecuaria y artesanal entre pequeños poblados productores y núcleos urbanos (ciudades). Desde los pequeños mercados semanales dispuestos en las parroquias provinciales, los comerciantes transportaban a lomo de mula o en carretas las mercancías y géneros de producción hacia centros urbanos más complejos que cumplían el papel de centros de acopio regional, en donde otros comerciantes se aprovisionaban de éstas para transportarlas a mercados situados en ciudades a larga distancia o hacia los puertos en las ciudades costeras, todo ello a través de improvisados y deficientes caminos.

Para la provincia del Socorro el antiguo Camino Real servía de vía de conexión con las poblaciones de Girón, San Gil, Vélez, Pamplona y otros lugares(8), permitiendo unir pueblos, villas y ciudades entre sí mediante la realización de operaciones comerciales en los mercados. La dinámica de la producción y la comercialización generada en la zona, despierta el interés de sus autoridades y pobladores por la reparación y adecuación de los caminos y la construcción de puentes, en aras de reforzar y expandir los vínculos comerciales regionales(9). (Ver Esquema vial de la ciudad del Socorro en el siglo XVIII).

Para las provincias como el Socorro cuyo crecimiento y desarrollo no dependieron de la minería, María Teresa Uribe y Jesús Álvarez plantean que la comercialización de sus productos internos funcionó a nivel de mercados de tres maneras: en primer lugar, como mecanismo de consecución de las monedas de oro para pagar las importaciones; en segundo lugar, como mecanismo de distribución de las materias primas utilizadas en los centros artesanales, como los cueros, el algodón, la lana, las maderas, etc.; y en tercer lugar, como mecanismo de distribución de los productos artesanales y de alguna producción primaria que por sus características no se produce en todos los climas y en todas las latitudes, como el cacao, o cuando se trata de productos gravados por el 


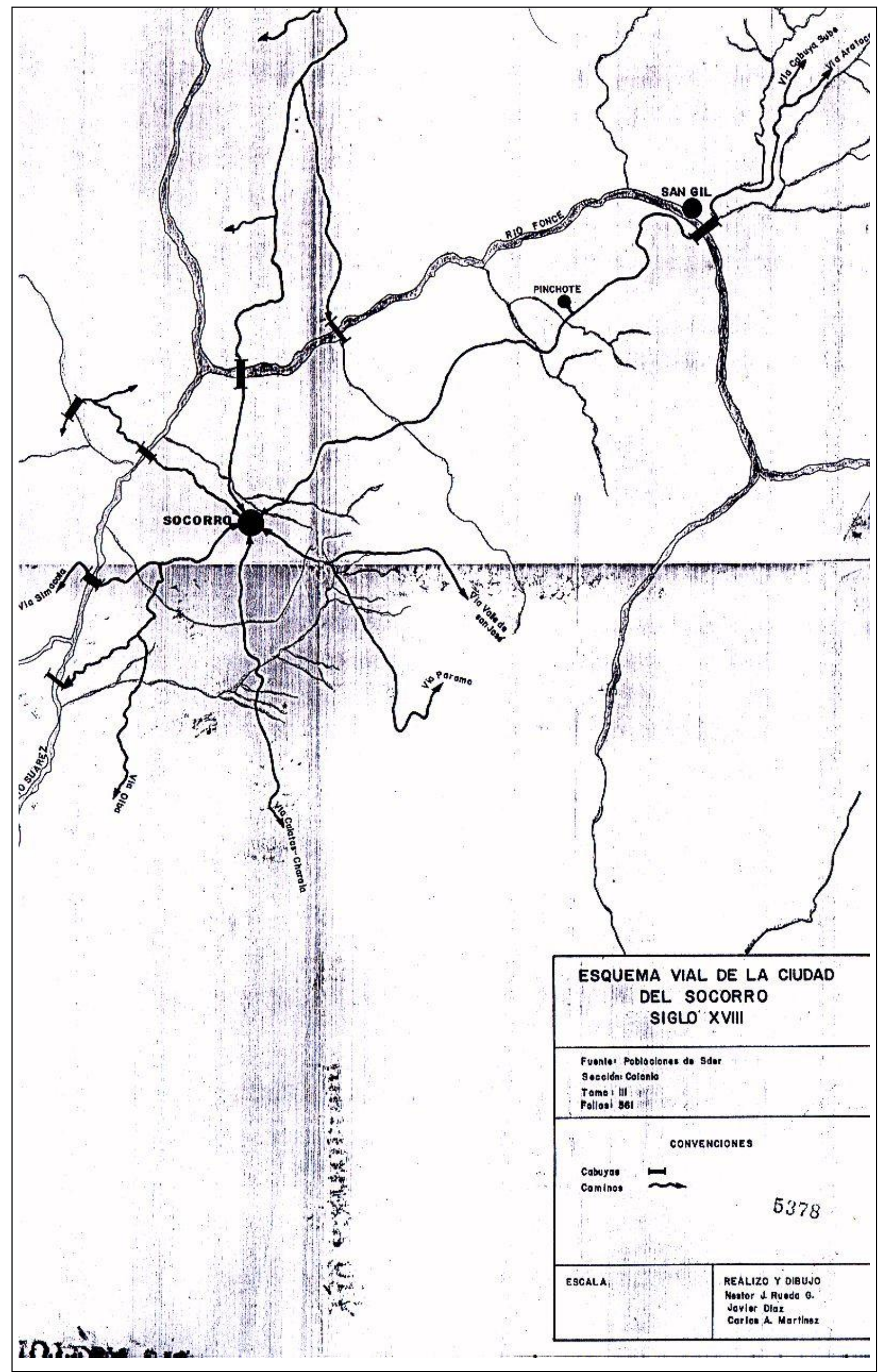


estanco como el tabaco, la sal y el aguardiente(10). Vemos entonces que el comercio de productos internos genera toda clase de mercados regionales estrechamente vinculados a la relación dinero(oro o plata)-mercancía que empiezan a configurar una incipiente economía de carácter nacional a través de la dinámica de los mercados.

Varias han sido las condiciones señaladas por los historiadores que posibilitaron el surgimiento de la producción manufacturera en la provincia durante el periodo colonial. En términos generales podemos resumirlas de la siguiente manera:

1. El establecimiento de los invasores hispánicos en los antiguos poblados indígenas y la continuidad dada a la producción agrícola y artesanal ya existente, sumada al trabajo pecuario con la expansión del ganado y los rebaños de ovejas. Todo esto generado por el desplazamiento de la fuerza de trabajado y la inversión de capitales ante el fracaso de la producción minera.

2. A la existencia de una abundante materia prima se sumó la disposición de la fuerza de trabajo indígena, el funcionamiento de la mita textil y los inicios de un incipiente mercado de intercambio de tipo local. Y por último,

3. La expansión de la demanda de manufacturas que llegó a conformar un mercado amplio que superó el ámbito local para articularse al mercado regional y nacional.

Entre las condiciones políticas que rodearon la formación del sector manufacturero, podemos destacar el papel que cumplió el Estado colonial, en su doble intención, que inicialmente, a pesar de promover y fomentar el trabajo manufacturero y obrajero indígena, termina por suprimirla paulatinamente con el único propósito de eliminar la competencia para el comercio de España(11). Dicha prohibición a la mita industrial, que daría la puntada final a la producción obrajera indígena fue formulada en la Real Cédula para todas las colonias españolas en el Nuevo Mundo: "Habiendo sido informados de que en los obrajes de paños de la 
Nueva España han resultado algunos inconvenientes, por el mal tratamiento y agravios que reciben los indios, y que se ha introducido comerciarlos en el Perú, enflaqueciendo el trato y comercio con estos reynos, donde en su fábrica y labor se pone la atención que conviene: Ordenamos a los Virreyes de la Nueva España, que en todo lo posible procuren relevar a los indios de este trabajo pues aunque siempre le han de tener voluntarios, y por sus jornales bien pagados, y con toda libertad, importará menos que cese la fábrica de los paños, que el menor agravio que pueda recibir; y por conveniencia del comercio de estos Reynos de Castilla, no se debe permitir su aumento, ni continuarlo con el Perú"(12). El argumento del maltrato indígena empleado por la Corona, aunque pudo ser cierto, buscaba disfrazar la intención de no dejar rivalizar la producción de textiles en las colonias con los producidos en la península, sacando a los primeros de la competencia y permitiendo la continuidad de las importaciones hacia el nuevo continente. Tirado Mejía cree que detrás de tales medidas existían los intereses paternalistas de la Corona española que ocultaban sus intereses de explotación, pues más cruel había sido la mita minera pero como convenía a los intereses españoles no fue suprimida(13). No obstante, otros autores no están de acuerdo con esta posición y comparten las humanitarias intenciones de la Corona española frente a la situación de explotación indígena en las colonias(14).

Lo cierto de todo es que en el siglo XVIII la producción de manufacturas parece cambiar de escenario, desplazándose de Tunja a la cálida región del Socorro en tierras santandereanas. Por otro lado, con la expulsión de los jesuitas en la segunda mitad de este siglo, la producción manufacturera en el Casanare inicia su proceso acelerado de decadencia(15).

Por ello, a mediados del siglo XVIII es muy difícil encontrar rastros del trabajo obrajero y de su constitución misma, es decir, como institución industrial de notable incidencia en la economía de un determinado lugar, como si sucedía en Perú y la Nueva España. A continuación vamos a dar un breve vistazo sobre la implantación del obraje en la Nueva Granada, su desarrollo y los efectos a que 
esta nueva forma de trabajo y explotación indígena conlleva. Estimo conveniente conocer un poco acerca del origen y desarrollo de esta forma de explotación indígena, los lugares en los cuales floreció, su papel en la producción artesanal, y el porqué la provincia del Socorro no fue partícipe de esta forma de trabajo organizada en el periodo colonial.

\section{La Implantación de los Obrajes en el Nuevo Reino de Granada}

Con la introducción a las colonias de nuevas fibras como la seda y la lana por parte de los españoles para la producción artesanal de nuevos productos, se requería importar tanto la maquinaria adecuada como a los sastres que pudieran capacitar al indígena en el uso de ésta. Los primeros sastres optaron por establecer pequeños talleres manufactureros que los hizo convertirse en patrones que empleaban a los indígenas haciéndolos trabajar largas jornadas con pagas muy bajas. Las grandes ganancias que se obtenían de esto resultaron muy atractivas para muchos otros españoles, quienes no tardaron en establecer sus propios talleres, más tarde llamados talleres artesanales, gremios, obrajes de paño, o simplemente obrajes. De esta manera, los obrajes se constituyeron en talleres de producción en los que se reunía una cantidad considerable de indígenas con el objetivo de desempeñar diversas labores artesanales, en especial la fabricación de mantas y textiles de lana y algodón.

Vemos entonces que la producción textil manufacturera con base en obraje y batán, se remonta a los inicios de la colonización. En esta materia la Corona española dispuso que a partir de las tasas de 1571 y 1572 se obligara a los indígenas a hilar no sólo mantas de algodón sino también de lana y se encargó a los encomenderos a proporcionar la lana en bruto(16), correspondiéndole al pueblo de indios construir los obrajes y las acequias para las aguas que necesitaba el batán(17). En un principio los indígenas debían prestar este servicio 
bajo la obligación de la mita, y luego se generalizó su funcionamiento por una especie de contrato en el que los indígenas ponían su trabajo y recibían a cambio un salario o su participación en especie(18). Los primeros encomenderos en tierra santandereana que aprovecharon la fuerza de trabajo indígena obtuvieron de ésta y de su organización en incipientes talleres los primeros productos de manufactura con base en el algodón cultivado por los indios y la lana traída por los españoles y que ya empezaba a obtenerse fácilmente con la traída de ovejas del viejo mundo. De esta manera, hubo "batán de lana y producción de lienzos de algodón y alpargates"(19).

Sastres, maestros, artesanos, encomenderos y estancieros aprovecharon la experiencia indígena en el hilado y tejido, montando obrajes para la producción de telas de algodón y lana, al mismo tiempo esta producción se animó con la demanda de estos géneros(20). El impulso inicial y el trabajo fue tanto que los obrajes y los gremios en donde se producían desde las prendas más rudimentarias, hasta las telas más elaboradas tipo europeo, crecieron de tal manera, que la competencia no era ya entre indígenas y españoles, sino entre los españoles mismos, quienes habían establecido ya toda una industria textil. Documentos conservados hasta nuestros días nos dan cuenta de dichas actividades en el repartimiento de Chía en el actual departamento de Cundinamarca: "Don Andrés, cacique, Francisco Fagua, Juan Caña, Juan Buqueno, Hernando de Nifro y otros capitanes y principales del repartimiento de Chía y el encomendero Juan Arrieta acordaron el 6 de julio de 1598 en dicho pueblo se haga y funde un obraje y batán con los que usan en la ciudad de Quito, donde se hagan paños y rejas y toda la demás ropa que se pudiera hacer"(21).

Los obrajes se constituyeron entonces en una forma de organización del trabajo indígena implantado por los españoles, destinado a la producción de tejidos de lana y algodón, siendo su base de apoyo el pueblo indígena mismo, del que se sustraía la mano de obra, los materiales para la construcción de los talleres y en la mayoría de los casos, las materias primas. 
Se tiene registro de la fundación de obrajes y batanes en las encomiendas de Vigua, Mátima, Nonocorá, La Palma, Guachipay, Suta, Oicatá, Socacá, Cogua, Engativá, Susa, Tensa, Tunja, Vélez, Tibasosa, Morcote y pacho, adscritas a la provincia de Tunja(22). La conformación de obrajes y talleres trajo consigo la necesidad de capacitar a los indígenas que trabajaban en ellos para un mejor desempeño laboral y una mejor utilización de la fuerza de trabajo al interior de las encomiendas y los repartimientos de indios, por ende, "se establecieron en las reducciones, escuelas y talleres de oficios, donde los indios aprendían a manejar tornos, sierras, fraguas, telares, y se hacían expertos en carpintería, esculturas, fundición y sastrería"(23). El indígena pasa de ser únicamente trabajador agrícola para convertirse en un hábil trabajador presto a las nuevos sistemas de explotación laboral que imponían los españoles. Los diversos oficios que desempeñaban los indígenas dejan en claro la existencia de una marcada división del trabajo al interior de los obrajes coloniales.

En la "Descripción de Tunja", citada por Ospina Vásquez, se menciona que en ese distrito había "ocho obrajes en que hay cinco batanes, lábranse en ellos sayales, frisas, frezadas y algunas jerguetillas y jergas para costales; lábranse en ella cada año 15000 varas de sayal; 7000 de frisas, 4000 de jerguetas y cordellate de jerga, 5400 frezadas. Vale la vara de sayal a tres tomines de oro de trece quilates, la de frisa a lo mismo, la de jergueta o cordellate a cinco tomines, la de jerga a dos; cada frezada a tres pesos... De lienzo de algodón se labran cada año en este distrito 8000 varas; vale cada vara a dos tomines..."(24).

Los obrajes florecieron en la Nueva Granada hasta el siglo XVIII, especialmente en las regiones de Tunja, Pasto y Casanare. Lamentablemente sobre la zona correspondiente a la provincia del Socorro para este periodo no se tiene información sobre la existencia de obrajes o talleres de producción de manufacturas de algodón y lana. Los registros españoles legados hasta nuestros días sobre esta región sólo admiten la producción realizada por los indígenas para 
sus encomenderos y la que destinaban para comercio e intercambio, más no registra la existencia de espacios arquitectónicos (obrajes y batanes) destinados exclusivamente al trabajo artesanal que contara con la infraestructura adecuada para tal fin, como sucediera en Boyacá, Pasto(25), Quito(26) y México(27), tal como lo demuestran los diversos trabajos de investigación sobre dichas zonas.

Hay que recordar que la base de la producción obrajera la constituía la energía laboral indígena, en la cual descansaban toda la variedad de oficios que se desempeñaban al interior del obraje o taller, ya fuese a cargo de indígenas adultos o niños sin distinción de sexo. Como ya se sabe(28), la meticulosa labor de exterminio étnico propiciada por el capitán Martín Galeano en los inicios de la conquista española en el territorio guane, sumado a un posible suicidio en masa y a epidemias causadas por las enfermedades traídas por los conquistadores a las nuevas tierras, condujo a la rápida disminución de la población aborigen del lugar, lo cual nos lleva a pensar que dicha ausencia de mano de obra se constituiría en la razón fundamental por la cual no se implantó, en la zona correspondiente a la provincia del Socorro y el resto de Santander, el sistema de producción obrajera, como si ocurrió en Tunja, Pasto y los Llanos orientales en donde se concentraba en gran número la fuerza laboral indígena. Para Mario Aguilera(29), "el decaimiento cuantitativo del indígena fue más fuerte y rápido en la comarca santandereana dado su escaso volumen originario -comparado con la región cundiboyacense- y el temprano mestizaje advertido por los cronistas. Aunque los datos de la jurisdicción de Vélez en 1757 son de por sí dicientes, es de anotar que hacia el interior del actual departamento de Santander, el proceso de declinación indígena fue parecido y tal vez más intenso. El resguardo de Chanchón (Socorro), por ejemplo, en 1642 contaba con 369 indios y entre ellos 99 tributarios. Y en 1751 no quedaban sino 16 indios con uno solo como tributario"(30).

Los pocos indígenas sobrevivientes fueron empleados inicialmente en el trabajo minero y después en actividades agropecuarias emprendidas luego del fracaso en las minas. Se cree que para finales del siglo XVII probablemente no quedaban 
más de 2000 indígenas guanes de una población que debió sobrepasar los 15000 a la llegada de los conquistadores españoles(31).

Como consecuencia de la rápida disminución de tributarios y fuerza de trabajo indígena, la población blanca y mestiza que aumentaba gradualmente se ve obligada a trabajar por sí misma tanto en labores agropecuarias como domésticas, continuando el trabajo artesanal legado de la cultura guane. Por otro lado, la rápida asimilación de las costumbres españolas por parte del indígena guane y el rápido mestizaje dado en la zona, permitió que esta "nueva raza" fusionara los comportamientos y las actividades cotidianas surgiendo de esta manera el artesano santandereano, conocedor de una tradición artesanal indígena y de unas arraigadas costumbres sociales y religiosas propias del invasor europeo. Esto explica la concentración del trabajo artesanal doméstico, que llevaba a cabo el artesano en su propia casa, que a la postre podía considerarse como su taller o lugar de trabajo. Herencia cultural sin duda legada a sus descendientes mestizos, que se convertiría en la actividad esencial de subsistencia y de adquisición de recursos de una nueva generación de familias de pequeños agricultores.

El nuevo tipo de campesino que empieza a formarse en la provincia del Socorro, y por que no en el Nuevo Reino, es descrito por Pedro Fermín de Vargas de la siguiente manera:

"En los distritos de Vélez, Socorro, San Gil, y Girón, en el que todavía no se ha dado lugar a las grandes haciendas, se ve mayor número de gentes que en las demás partes del Reino, y es porque repartidos sus habitantes en pequeñas heredades, cuya propiedad les pertenece, las cultivan con el mayor interés. Sin embargo, de no haber allí minas algunas, se mantiene la gente con más aseo, se multiplica la población; la labranza, aunque imperfecta se halla en mejor pie que en otras partes; se advierte más civilidad en el pueblo y en sus habitantes más gustosos. Atribuyo esta diferencia a la 
fábrica de lienzos que asegura el sustento al tejedor, a la hilandera y al labrador que siembra el algodón, que es su verdadera mina"(32).

La concentración del trabajo artesanal socorrano en el propio domicilio del artesano, hacía de ésta una labor particularmente doméstica, de amplia participación familiar, con una división interna del trabajo, un espacio familiar que se constituía, además de sitio de residencia y convivencia, en taller de producción artesanal. De allí que, para el profesor David Johnson(33), la razón por la que los artesanos santandereanos eran considerados como profundamente individualistas, radicaba en que la gran mayoría de ellos trabajaba en sus hogares o en pequeños talleres, lo que los hacía poco partícipes de organizaciones o sociedades que propugnaran por mejorar sus condiciones laborales y económicas.

El trabajo doméstico y familiar del artesano de la provincia del Socorro iría a constituir con el tiempo la base de la producción manufacturera de la región oriental de la Nueva Granada, que surtiría no solamente los mercados de dicha región, sino que también alcanzaría otros circuitos comerciales distantes como los ubicados en los puertos del río Magdalena y los distritos mineros de la región de Antioquia. Los bajos precios alcanzados por las manufacturas socorranas en los mercados hacían que éstas se constituyeran en las preferidas de las clases populares y de aquellos que se sentían orgullosos de vestir productos de "la tierra" frente a los ya conocidos y refinados textiles ingleses que empezaban a inundar los mercados locales a finales del siglo XVIII.

Cincuenta años después, a mediados del siglo XIX, las políticas económicas de los gobiernos liberales de la nueva república, serían las encargadas de inclinar la balanza a favor del laissez faire, ahogando de una vez por todas la producción artesanal de la provincia del Socorro que no tenía como competir con los productos industrializados ingleses que acaparaban los bajos precios en el mercado. Pero esa es otra historia. 


\section{CITAS Y NOTAS}

* Historiador Universidad Industrial de Santander (Colombia). Catedrático Escuela de Historia Universidad Industrial de Santander.

1. STOLLER, Richard Jon. Liberalism and Conflict in Socorro, Colombia, 18301870. Ph. D. Thesis, Duke University, 1991. p. 34.

2. AGN, Sección República, Fondo Gobernación Socorro, Rollo, 430, f. 631.

3. MARTínEZ, Armando, et al. Historia de la Subregionalización de los Santanderes. Bucaramanga: Colciencias - Universidad Industrial de Santander, 1994.p. 20.

4. JOHNSON, David. Santander siglo XIX: cambios socioeconómicos. Bogotá: Carlos Valencia, 1984. p. 122.

5. URIBE, María Teresa y ALVAREZ, Jesús. Poderes y Regiones: Problemas en la constitución de la nación colombiana 1810-1850. Medellín: Universidad de Antioquia, 1987. p. 34-35.

6. Ibid. p. 35-36.

7. GUZMÁN, Ángela. Poblamiento y Urbanismo Colonial en Santander. Bogotá: Universidad Nacional de Colombia, 1987. p. 78-79.

8. AGN. Sección Colonia. Fondo Mejoras Materiales. Tomo 1. Citado por GUZMÁN, Ángela. Op. cit., p. 79.

9. Ángela Guzmán, basándose en el fondo de Mejoras Materiales del Archivo General de la Nación, reseña un completo listado de obras civiles que se desarrollaron en la provincia y poblaciones adyacentes durante el periodo colonial. Op. cit. p. $79-82$.

10. URIBE, María Teresa y ALVAREZ, Jesús. Poderes y Regiones: problemas en la constitución de la nación colombiana 1810 - 1850. Medellín: Universidad de Antioquia, 1987. p. 41-42. 
11. TIRADO MEJÍA, Álvaro. Introducción a la Historia Económica Colombiana. Bogotá: El Ancora, 1988. p. 36-37.

12. Recopilación de Leyes de Reinos de Indias. Ley IV. Título XXVI, Libro IV. Citado por: Tirado Mejía, Op. cit., p. 37.

13. TIRADO MEJÍA, Álvaro. Op. cit., p. 36.

14. OSPINA VÁSQUEZ, Luis. Industria y Protección en Colombia 1810 - 1830. Bogotá: Oveja Negra, 1974. p. 95-96.

15. TIRADO MEJÍA, Álvaro. Op. cit., p. 252.

16. COLMENARES, Germán. Historia Económica y Social de Colombia. Bogotá: Tercer Mundo, 1998. p. 134.

17. COLMENARES, Germán, et al. Fuentes Coloniales para la Historia del Trabajo en Colombia. Bogotá: Universidad de los Andes, 1968. p. 431-492.

18. TIRADO MEJÍA, Álvaro. Op. cit., p. 251.

19. GUERRERO, Amado y MARTINEZ, Armando. La Provincia de los Comuneros: orígenes de sus poblamientos urbanos. Bucaramanga, Universidad Industrial de Santander, 1997. p. 79.

20. ESCOBAR, Carmen. La Revolución Liberal y la Protesta del Artesanado. Bogotá: Fondo Editorial Sudamérica, 1990. p. 47-48.

21. COLMENARES, Germán, et al. "Fuentes Coloniales...". p. 436-437. 22. Ibid., p. 445-488.

23. LIEVANO AGUIRRE, Indalecio. Los Grandes Conflictos de nuestra Historia. Bogotá: Editorial Prensa Nueva, 1984. Libro II. p. 107.

24. OSPINA VASQUEZ, Luis. Op. cit., p. 94.

25. COLMENARES, Germán, et al. "Fuentes Coloniales...". Op. cit., p. 436-488.

26. CAILLAVET, Chantal. La Artesanía Textil en la Época Colonial. EN: Cultura. Vol. VIII. No. 24b. Enero-Abril. Quito: Banco Central de Ecuador, 1986. p. 521-527. 27. MIÑO, Manuel. "Manufactura Colonial: aspectos comparativos entre el obraje andino y el novohispano. EN: BONILLA, Heraclio. (Ed). El Sistema Colonial en la América Española. Barcelona: Crítica, 1991. p. 103-153.

28. GUERRERO, Amado y MARTíNEZ, Armando. Op. cit., p. 80; MARTíNEZ, Armando, et al. Op. cit., p. 392-393; JOHNSON, David. Op. cit., p. 120-121. 
29. AGUILERA PEÑA, Mario. Los Comuneros: guerra social y lucha anticolonial. Bogotá: Universidad Nacional, 1985. p. 34-36.

30. Ibid., p. 35.

31. GUILLÉN MARTíNEZ, Fernando. El Poder Político en Colombia. Bogotá: Planeta, 1996. p. 156.

32. DE VARGAS, Pedro Fermín. Pensamientos Políticos y Memoria sobre la Población del Nuevo Reino de Granada. Citado por GUILLÉN MARTÍNEZ, Fernando. Op. cit., p. 157-158.

33. JOHNSON, David. Op. cit., p. 143.

\section{FUENTES}

\section{ARCHIVO}

Archivo General de la Nación (AGN). Sección Colonia. Fondo Virreyes. Rollo 16. EN: Centro de Documentación e Investigación Histórica Regional CDIHR, Universidad Industrial de Santander.

Archivo General de la Nación (AGN). Sección República. Fondo Socorro. Rollo 430. EN: Centro de Documentación e Investigación Histórica Regional CDIHR, Universidad Industrial de Santander.

Archivo Notarial del Socorro (ANS) EN: Centro de Documentación e Investigación Histórica Regional CDIHR, Universidad Industrial de Santander.

\section{BIBLIOGRAFICAS}


AGUILERA PEÑA, Mario. Los Comuneros: guerra social y lucha anticolonial. Bogotá: Universidad Nacional de Colombia, 1985.

ALVAREZ OROZCO, René. Los Textiles en el Socorro: del poblamiento hispánico a las reformas liberales del siglo XIX. Tesis Historiador. Bucaramanga: Universidad Industrial de Santander, 2001.

BRUNGARDT, Maurice Philip. Tithe Production and Paterns of Economic change in Central Colombia: 1764 - 1833. Tesis Doctoral. Austin: The University of Texas, 1974.

CAILLAVET, Chantal. La Artesanía Textil en la Época Colonial. EN: Cultura. Vol. VIII. No. 24b. Enero-Abril. Quito: Banco Central del Ecuador, 1986.

CERON, María Cristina y GELVES, Elizabeth. Demografía Histórica del Socorro en el Periodo Colonia 1684 - 1810. Tesis Historiador. Bucaramanga: Universidad Industrial de Santander, 1997.

COLMENARES, Germán, et al. Fuentes Coloniales para la Historia del Trabajo en Colombia. Bogotá: Universidad de los Andes, 1968.

Bogotá: Tercer Mundo, 1998.

Historia Económica y Social de Colombia. 1537 - 1719.

ESCOBAR, Carmen. La Revolución Liberal y la Protesta del Artesanado. Bogotá: Fondo Editorial Sudamericana, 1990.

GUERRERO RINCÓN, Amado y MARTíNEZ GARNICA, Armando. La Provincia de los Comuneros: orígenes de sus poblamientos urbanos. Bucaramanga: Universidad Industrial de Santander, 1997.

GUILLÉN MARTíNEZ, Fernando. El Poder Político en Colombia. Bogotá: Planeta, 1996.

GUZMÁN, Ángela Inés. Poblamiento y Urbanismo Colonial en Santander. Bogotá: Universidad Nacional de Colombia, 1987.

JOHNSON, David. Santander siglo XIX: cambios socioeconómicos. Bogotá: Carlos Valencia Editores, 1984.

LIEVANO AGUIRRE, Indalecio. Los Grandes Conflictos de Nuestra Historia. Bogotá: Prensa Nueva, 1984. Tomo 2.

MCFARLANE, Anthony. Colombia antes de la Independencia. Bogotá: Banco de la República - El Ancora, 1997. 
MARTINEZ GARNICA, Armando, et al. Historia de la Subregionalización de los Santanderes. Bucaramanga: Colciencias - Universidad Industrial de Santander, 1994.

Consideraciones Históricas sobre la fabricación de las mantas Muiscas y Guanes. EN: Estudio No. 137, Junio. Bucaramanga: Academia Santandereana de Historia, 1987.

MIÑO GRIJALVA, Manuel. Espacio Económico e Industria Textil. EN: Historia Mexicana. No. 128, Vol. XXXII, Abril-Junio. México: El Colegio de México, 1983.

. Manufactura Colonial: aspectos comparativos entre el obraje andino y el obraje novohispano. EN: BONILLA, Heraclio. (Ed.) El Sistema Colonial en la América Española. Barcelona: Crítica, 1991.

PHELAN, John Leddy. El Pueblo y el Rey. Bogotá: Carlos Valencia Editores, 1980.

RAYMOND, Pierre y BAYONA, Beatriz. Historia del Algodón en Santander. Bucaramanga: Banco de la República, 1996. p. 7.

STOLLER, Richard Jon. Liberalism and Conflict in Socorro, Colombia, 1830 1870. Ph. D. Thesis. Duke University, 1991.

TAVERA DE TÉLLEZ, Gladis. Tejido Precolombino, Inicio de la Actividad Femenina. EN: Historia Crítica. No. 9. Enero - Junio. Bogotá: Universidad de los Andes, 1994.

TIRADO MEJÍA, Álvaro. Introducción a la Historia Económica de Colombia. Bogotá: El Ancora, 1988

URIBE, María Teresa y ALVAREZ, Jesús. Poderes y Regiones: problemas en la constitución de la nación colombiana 1810-1850. Medellín: Universidad de Antioquia, 1987. 